\title{
As potencialidades do computador para o ensino da Matemática em um grupo de estudos
}

Luciano Feliciano de Lima*

\section{Resumo}

Este artigo apresenta o relato de uma pesquisa que buscou entender o ensino da Matemática com a utilização de computadores em um grupo de estudos. Também discute duas atividades desenvolvidas por uma equipe formada por professores dessa matéria na rede estadual de ensino, por licenciandos em Matemática pela Universidade Estadual de Goiás e por um professor pesquisador dessa instituição. $\mathrm{O}$ grupo estudou e planejou atividades geradas a partir dos softwares gratuitos Winplot e Geogebra. Dessas atividades, são apresentadas, aqui, duas: a primeira, sobre o quadrado; e a outra, sobre as funçóes trigonométricas seno e cosseno. Cada uma delas é seguida de consideraçóes dos participantes do grupo. A fim de mostrar parte do trabalho desenvolvido, é feita uma pequena discussão teórica sobre o uso do computador na escola, destacando-se os motivos para a escolha dos programas selecionados, a opção metodológica de cunho qualitativo, as características de um grupo de estudos e sobre o grupo formado, as preocupaçóes dos pesquisadores com a abordagem pedagógica, utilizando computadores, e as reflexóes do próprio grupo sobre duas atividades elaboradas. Este artigo destaca que a dinâmica de grupos de estudos de professores de Matemática pode ser uma forma eficiente para se discutir as dificuldades relacionadas ao trabalho docente e para a busca de alternativas pedagógicas para o ensino e para a aprendizagem dessa disciplina.

Palavras-chave: grupo de estudos, computadores em sala de aula, educação matemática.

The computer in a study group for the teaching of Mathematics

\begin{abstract}
This article presents a report on a study which set out to understand how Mathematics can be taught using computers in a study group. It also discusses two activities undertaken by a team made up of Mathematics state school teachers, Mathematics undergraduates at the State University of Goias and a research professor at that institution. The group studied and planned activities using free software, Winplot and Geogebra. Two of these activities are presented: one on the square and the other on the trigonometric sine and cosine functions; and
\end{abstract}

* Professor mestre da Universidade Estadual de Goiás (UEG). E-mail: lucianoebenezer@yahoo.com.br. 
each is followed by reflections from the group participants. In order to show a part of the work undertaken a short theoretical discussion is presented on the use of computers in the school, highlighting the reasons for the choice of programs selected, the choice of qualitative methodology, the characteristics of a study group and the group formed, the concerns of researchers as regards educational approaches using computers and the group's own reflections on the two activities carried out. This paper highlights the fact that the dynamics of study groups of Mathematics teachers could be an efficient way to discuss difficulties involved in teaching and searching for pedagogical alternatives for the teaching and learning of this subject.

Keywords: Study Group, computers in the classroom, Mathematical Education

\section{Introdução}

É apresentado aqui o relato de uma pesquisa que buscou entender o ensino da Matemática utilizando computadores em um grupo de estudos. Esse grupo foi formado por professores de Matemática da rede pública estadual, por licenciandos da Universidade Estadual de Goiás e por um professor dessa universidade, e foi denominado por seus membros como Senu + Positivo.

O objetivo deste artigo é demonstrar que um grupo de estudos pode ser um espaço para que professores discutam e elaborem possibilidades para o ensino de Matemática em um ambiente "informático". Para isso, discutem-se o uso do computador na escola, as preocupaçóes com o tipo de abordagem para uma maior participação dos alunos na sala de aula e comentam-se duas atividades elaboradas por esse grupo.

\section{Os professores e o computador na escola}

A questão de se utilizar computadores para o ensino vem sendo discutida no Brasil desde a década de 1980. Nesse período, açóes governamentais como o Educom (COMputadores na EDUcação), o Projeto Formar e o Proninfe (Programa Nacional de Informática na Educação) visam a capacitação de professores para o uso do computador em sala de aula. Contudo, em se tratando de professores de Matemática, o uso do laboratório de informática ainda é bastante restrito, principalmente em cidades distantes das metrópoles. Diante disso, Borba e Penteado (2001, p. 27) consideram ser

preciso enfatizar que, num país com as dimensóes do Brasil, não é possível pensarmos num programa nacional de informática que seja adequado a to- 
das as escolas. O sucesso das açôes de larga escala depende, em muito, de sua articulação com açóes isoladas. Será através dessa articulação que poderemos ter uma área de informática educativa em consonância com as particularidades de cada região brasileira e, através dela, ampliaremos constantemente, o limite do que é possível e do que é necessário ao que concerne o uso da tecnologia informática nas escolas.

Kenski (2007), ao abordar educação e tecnologias, defende a organização de situações em que se reflita sobre possibilidades de aprendizagem coletiva com a utilização das tecnologias da informação e comunicação (TIC). Para a autora, os professores utilizam pouco o computador na escola em atividades de ensino - porém, ela lembra que tal restrição não é exclusiva desses profissionais. Outros fatores dificultam a utilização desses equipamentos na escola, como: difícil acesso ao laboratório, número insuficiente de recursos tecnológicos para o uso, falta de manutenção dos equipamentos, programas obsoletos por falta de investimentos (destaque-se que isso ocorre com maior intensidade em escolas públicas em que os recursos para a aquisição de novos softwares são consideravelmente baixos) e formação deficiente para o uso de TIC para o ensino.

O computador e as possibilidades que ele oferece implicam repensar formas de aprender e produzir conhecimento. São máquinas que, conectadas à rede mundial de computadores, ou seja, com acesso à Internet, podem ser utilizadas para a educação, para o lazer, para o trabalho e também para outros fins. $\mathrm{O}$ alcance de sua funcionalidade é dado pelos limites da criatividade humana. O filósofo Lévy (1998, p. 28), ao refletir sobre o impacto do computador e da Internet na produçáo de conhecimento, argumenta que a interação entre seres humanos no ciberespaço cria uma inteligência coletiva que "é uma inteligência distribuída por toda parte, incessantemente valorizada, coordenada em tempo real, que resulta em uma mobilização efetiva das competências".

Em relação às possibilidades que o computador oferece à educação, Valente (2003, p. 02) destaca três características: "meio para representar e construir novos conhecimentos, para buscar e acessar informação e para se comunicar com outras pessoas, ou estabelecer relaçóes de cooperação na resoluçáo de problemas". Segundo o autor, "conhecimento é o que cada indivíduo constrói como produto do processamento, da interpretação, da compreensão da informação". (idem). Associado a isso, não se pode esquecer de 
que cada ser humano aprende de uma forma particular que depende, dentre outros fatores, da cultura que possui.

Ao tratar da inserção de tecnologias em um curso de formação inicial de professores de Matemática, Ponte, Oliveira e Varandas (2003) consideram que o uso de TIC em sala de aula de Matemática pode seguir caminhos distintos, conforme a postura pedagógica que se adote. Assim, se ela for mais tradicional, o professor utilizará o computador para fornecer informaçóes, controlar o ambiente da sala e para padronizar a forma como os alunos desenvolvem determinadas atividades. Mas se a postura for mais inovadora, há a preocupação com a criação de situaçôes de aprendizagem, de desafiar e apoiar os alunos e de valorizar os caminhos diferentes, adotados por eles, para resolverem suas tarefas.

Aqui, não há a intenção de dizer que a informática é a solução dos problemas educacionais, tampouco que ela seja o único meio de fazer com que os alunos sejam agentes ativos da própria aprendizagem. Aprender em um ambiente informatizado é diferente de aprender em um ambiente de lápis e papel, porém um não substitui o outro e é necessário que os alunos tenham contato com situaçóes variadas para promover o próprio desenvolvimento. Esse grupo de estudos concorda com Lima (2009, p. 36), quando ele aponta que,

ao considerar as possibilidades de ensino com o computador, o que pretendo é destacar que a dinamicidade desse instrumento pode ser utilizada para que os alunos trabalhem como se fossem pesquisadores, investigando os problemas matemáticos propostos pelo professor e construindo soluçôes ao invés de esperarem um modelo a ser seguido.

Diante do exposto, nota-se que é necessário estabelecer um diálogo com o professor da escola básica sobre o ensino em um ambiente informatizado. Açóes desse tipo podem contribuir para a capacitação desses profissionais para o ensino no laboratório de informática, no que se refere ao conhecimento de softwares educacionais, ao conhecimento pedagógico do conteúdo e à gestão do ambiente informatizado. Para isso, foram escolhidos os softwares Geogebra e Winplot, pois eles permitem experimentaçóes para tentativas de tirar conclusóes sobre determinados conteúdos de geometria e de álgebra. 


\section{A metodologia adotada, o grupo de estudos e suas características}

A pesquisa, da qual se originam as propostas de atividades para o uso do computador na aula de Matemática, ocorreu no período de maio de 2009 a maio de 2010. Os participantes foram convidados por meio de mensagens eletrônicas encaminhadas pelo Núcleo de Tecnologia Educacional (NTE) de Goiás, que apoiou a pesquisa. As atividades elaboradas por esse grupo tinham como público-alvo os alunos da segunda fase do Ensino Fundamental e do Ensino Médio.

A presente pesquisa insere-se no paradigma qualitativo e interpretativo. André (1983, p. 66) reforça que há muitas vantagens nesse paradigma de investigação para a área educacional, como "capturar os diferentes significados das experiências vividas no ambiente escolar de modo a auxiliar a compreensão das relaçóes entre os indivíduos, seu contexto e suas açóes". Esse é o objetivo que se almeja alcançar neste trabalho.

A escolha por trabalhar com o paradigma qualitativo pode ser explicada a partir da caracterização adotada por Alves-Mazzotti e Gewansdsznadjder (1998, p. 131). De acordo com eles, nesse modo de investigar, assumese "que as pessoas agem em função de suas crenças, percepçóes, sentimentos e valores e que seu comportamento tem sempre um sentido, um significado que não se dá a conhecer de modo imediato, precisando ser desvelado". Isso implica que a abordagem requer do pesquisador a capacidade de se envolver com o objeto de estudo e, por meio de interpretaçóes, produzir "um texto zelosamente escrito, com perspicácia e competência científicas, [que mostre] os significados patentes ou ocultos do seu objeto de pesquisa" (Chizzotti, 2003, p. 221). Por centrar-se na observação e na compreensão do pesquisador, esse método foi adotado para o presente trabalho.

Um grupo de estudos pode ser definido como a reuniáo de pessoas que têm interesse em estudar um assunto específico. No grupo aqui tratado, busca-se entender como utilizar o computador para o ensino da geometria plana e de funçóes. Para Ferreira (2003), Fiorentini (2004), Gimenes (2006) e Murphy e Lick (1998), os componentes do grupo estabelecem objetivos e se engajam para alcançá-los. Para que isso ocorra, a participação deve ser voluntária. Nesse ambiente, o desejo de compartilhar saberes e experiências é uma constante e todos são considerados iguais para contribuir com ideias, críticas e sugestóes, a qualquer 
momento. Há um respeito mútuo às opinióes do outro, tendo em vista o desenvolvimento do grupo.

Baseado em Fiorentini (2004), Ferreira (2003), Gama (2007) e Lima (2009), esse grupo de estudos teve como princípios: a participação voluntária; o compartilhamento dos mesmos objetivos e a busca para alcançá-los; a organização de uma pauta para cumprimento de tarefas, garantindo que o tempo de reunião fosse o mais produtível possível; iguais possibilidades de participação dos componentes, em que a comunicação fosse aberta, ou seja, estímulo às ideias e opinióes diferentes e até opostas; incentivo ao respeito mútuo, à tolerância e à colaboração, para possibilitar um melhor desenvolvimento do próprio grupo. Além disso, houve a constante preocupação em solucionar problemas relativos à forma de realização e funcionamento do trabalho e, após serem aplicadas as fichas aos alunos da escola-campo, houve momentos para leituras, discussóes e produção de fichas de atividades e de reflexão sobre a prática. Esse tipo de ambiente abre espaço para a reflexão, permitindo uma integração entre prática e teoria, o que possibilita o desenvolvimento profissional dos participantes. De acordo com Gimenes e Penteado (2008, p. 88), a reflexão propiciada em um grupo de estudos permite "voltar atrás e rever os acontecimentos e as práticas. Rever aquilo que vem sendo feito em sala de aula e, dessa forma, criar condiçóes favoráveis para mudanças".

Conforme Murphy e Lick (1998), em um grupo de estudos, os professores podem: a) estudar artigos, literaturas, pesquisas e informaçóes das agências de educação regionais, estaduais e nacionais; b) investigar abordagens pedagógicas, assim como possíveis materiais a serem utilizados em sala de aula; c) desenvolver as abordagens em suas aulas. Assim, considera-se que aplicar o que se está planejando contribui para que o grupo reflita sobre o próprio planejamento e o refaça quando achar necessário. Por isso, essa foi a dinâmica que o grupo Senu + Positivo adotou.

O nome Senu + Positivo (leia-se Senu mais Positivo) foi escolhido pelos membros para representar algo que estava acontecendo e que acrescentava conhecimento prático e reflexivo a todos, um conhecimento tanto pedagógico quanto de conteúdo matemático. Todos concordaram que o sinal + daria essa ideia de acréscimo. A expressão "senu" é uma forma coloquial interiorana de dizer sendo, ou seja, algo que está em movimento, que está se formando. Foram estabelecidos como objetivos: aprender os comandos básicos dos programas Geogebra e Winplot e desenvolver atividades com características investigativas. 
O grupo Senu + Positivo é composto por nove pessoas: quatro professores residentes em Mozarlândia, três professores residentes na cidade de Goiás, uma licencianda e um professor do curso de Matemática da Universidade Estadual de Goiás (UEG). Aconteceram cinco encontros no Núcleo de Tecnologia Educacional (NTE) da cidade de Goiás. O primeiro encontro durou três horas e os demais tiveram a duração de sete horas cada.

A primeira reunião do grupo serviu para compartilhar como seriam desenvolvidos os trabalhos e para indicar os endereços na Internet em que os participantes poderiam baixar o programa a ser utilizado. Houve tempo também para combinar os horários dos próximos encontros. $\mathrm{O}$ intuito era que houvesse dez reunióes, com três horas cada, mas os professores chegaram à conclusão de que o ideal seria ocorrer mais quatro encontros, com duração de sete horas cada.

\section{O grupo e a abordagem pedagógica}

Desde o primeiro encontro, foi discutido o uso dos programas Geogebra e Winplot em aulas de Matemática. O grupo foi unânime ao declarar que é possível usá-los em sala. Contudo, ainda não haviam utilizado o laboratório de informática para ensinar essa matéria. É interessante destacar que as visóes dos participantes do senu + positivo se aproximavam das relatadas por Ribeiro e Ponte (2000), com relação ao estudo das concepçóes e práticas de professores de Matemática no uso das novas tecnologias. Afinal, sobre o computador em aulas de Matemática, entendiam que ele é útil: como motivador, pois anima os alunos e, consequentemente, melhora o ambiente da aula; como facilitador, porque permite realizar determinadas tarefas que demandariam um tempo muito maior se realizadas apenas com lápis e papel.

A relação entre o uso do computador em aulas de Matemática e a abordagem pedagógica utilizada também foi colocada em discussão. Isso motivou a leitura dos "Cenários para investigação" (Skovsmose, 2000). A ideia de cenários para investigaçáo contribuiu para que o grupo percebesse que não é suficiente o professor dominar o uso da informática educativa. Ele precisa associar esse uso a um planejamento que leva em conta a criação de ambientes de aprendizagem em que o aluno constrói o seu conhecimento. Como cenário para investigação, os participantes concordaram com 
Skovsmose (2000, p. 73), como sendo aquele em que se "convida os alunos a formularem questóes e formularem explicaçôes". Esse autor propõe seis ambientes de aprendizagem, considerando-os como uma simplificação das situaçóes que envolvem o trabalho do professor de Matemática. Tais ambientes podem ser vistos no Quadro 1.

Quadro 1: Ambientes de Aprendizagem (Skovsmose, 2000, p. 75)

\begin{tabular}{|l|l|l|}
\hline & Exercícios & Cenários para investigaçáo \\
\hline $\begin{array}{l}\text { Referências à } \\
\text { Matemática pura }\end{array}$ & $(1)$ & $(2)$ \\
\hline $\begin{array}{l}\text { Referências a } \\
\text { semirrealidades }\end{array}$ & $(3)$ & $(4)$ \\
\hline $\begin{array}{l}\text { Referências ao } \\
\text { mundo real }\end{array}$ & $(5)$ & $(6)$ \\
\hline
\end{tabular}

Como Matemática pura [(1) e (2)], na sala de aula, Skovsmose (2000) trata as tarefas que não fazem qualquer referência de aplicabilidade a uma situação concreta. Assim, as atividades propostas pelos professores, que fazem referência à Matemática pura, geralmente envolvem a utilização de axiomas, teoremas, algoritmos etc. Desse modo, as soluçóes das atividades privilegiam a estrutura da Matemática sem preocupação com uma aplicação real.

Quando se trata de semirrealidades [(3) e (4)], o autor explica que ela aparece nos enunciados de exercícios de Matemática quando não há qualquer preocupação em se apurar a veracidade das informaçóes. Parece se tratar de uma situação real, mas não é. Para exemplificar essa situação, a qual ele também trata como realidade virtual, recorre ao seguinte problema: "Pedro tem que comprar maçás. Ele trouxe uma nota de cinquenta reais. Ele tem que comprar 14 quilos e cada quilo custa 85 centavos. Quantos reais terá de troco?" (Skovsmose, 2000, p. 81). Para esse exemplo, o autor faz analogias com a vida real, já que um aluno poderia fazer tais relaçóes durante a resolução do exercício proposto. Dentre elas, está a dificuldade de se conseguir exatamente 14 quilos de maçâs ou a dificuldade enfrentada por Pedro para carregar esse peso. No mundo real, essas preocupaçóes pre- 
cisam ser levadas em consideração, mas tentativas de interpretação, visando relacionar o problema com uma situação real, não são relevantes em uma semirrealidade. $\mathrm{O}$ importante é traduzir matematicamente o enunciado e encontrar sua solução, que geralmente é única. Qualquer coisa diferente disso, no paradigma do exercício, pode ser considerada pelo professor como obstrução da aula.

Em relação aos ambientes [(5) e (6)], que fazem referência ao mundo real, Skovsmose (2000) trata de situaçóes-problema envolvendo dados empíricos. Tais dados, a serem analisados matematicamente pelos alunos, têm alguma relação com uma situação da vida real.

É importante destacar que o grupo decidiu iniciar elaborando atividades que se inserem no ambiente (2). Assim, depois de se sentirem mais familiarizados com as atividades da Matemática pura, em um ambiente informatizado, pensariam em outras atividades que se inserissem nos demais ambientes propostos por Skovsmose (2000). Contudo, o período das reunióes do grupo, de setembro a dezembro de 2009 , não permitiu a elaboração dessas atividades.

Com essa inquietação em mente, buscou-se desenvolver tarefas que demandassem maior envolvimento dos alunos na aula de Matemática. Esse envolvimento é almejado por grande parte dos professores, e no grupo Senu + Positivo não foi diferente. Os membros relataram que, em seu cotidiano profissional, parte dos alunos não se interessa pelo conteúdo ministrado. Há aqueles que conversam paralelamente durante as explicaçóes e é preciso chamar a atenção constantemente. Outros simplesmente não prestam atenção, e uma parcela consideravelmente pequena se mostra interessada na aula.

Diante desse quadro, a expectativa do grupo era de que as atividades elaboradas pudessem despertar o interesse na aula, motivada pela mudança de ambiente do lápis e papel para o do laboratório de informática. Esperava-se que a abordagem investigativa também contribuísse para que os alunos aceitassem o convite do professor para entender o que acontece com o problema estudado. Afinal, de acordo com Ponte, Brocardo e Oliveira (2003), ao investigarem matematicamente, os alunos procuram entender o problema, tentam levantar hipóteses que possam solucioná-lo, testam-nas e continuam nesse processo em busca da resolução do problema. Encontrada uma solução, eles a justificam ao professor e aos demais colegas, por meio 
do conhecimento matemático que possuem. Essa abordagem pedagógica possibilita um diálogo mais frequente em aulas de Matemática.

\section{As atividades elaboradas}

Quando foi proposto o primeiro planejamento, houve certa timidez dos professores, inicialmente. Eles não pareceram muito à vontade em planejar atividades para serem desenvolvidas por meio do computador. A ideia de realizar algo saindo de uma rotina à qual já se está acostumado não parece ser algo que se faça logo de imediato. Foi preciso esforço para pensar nos objetivos que se pretendia alcançar. Houve a necessidade de revisitar os textos discutidos para refletir sobre a aplicabilidade da teoria estudada na elaboração das tarefas. A preocupaçáo em elaborar questôes que não confundissem os alunos também estava presente. Afinal, o grupo esperava que, nesse ambiente novo, do laboratório de informática, os alunos se sentissem mais livres para experimentar e tirar suas conclusóes. Dificilmente, isso seria possível se o professor tivesse que ficar explicando, a todo o momento, o que é preciso fazer na atividade $\mathrm{x}$ ou na atividade $\mathrm{y}$.

Por exemplo, o Quadro 2 mostra a primeira atividade elaborada pelo grupo para o trabalho com o Geogebra. Ela foi pensada para alunos a partir do $6^{\circ}$ ano e seus objetivos envolvem: a) identificar os elementos do quadrado e b) entender quais são as características definidoras do quadrado. Como, provavelmente, seria o primeiro contato dos alunos com o computador e com o Geogebra para fazerem experimentaçóes matemáticas, preocupou-se em detalhar e em destacar em negrito o que deveria ser feito. Isso não significa esperar que os alunos façam a tarefa sem qualquer ajuda do professor. Com certeza, as dúvidas surgiriam e orientaçóes precisariam ser dadas. No entanto, esperava-se que, ao explicitar os comandos que deveriam ser seguidos, os alunos começassem a se acostumar com as orientaçóes dadas por escrito. Os participantes comentaram que, quando as crianças ou os adolescentes têm dúvida sobre algum programa de computador, eles realizam buscas em sites de pesquisa da Internet e geralmente encontram orientaçóes disponibilizadas por outros, que os auxiliam em suas dificuldades. E destacaram: é pouco provável que peçam ajuda a pais ou professores para orientá-los sobre o que fazer. Assim, a expectativa do grupo foi de que as orientaçóes dispostas nas atividades auxiliassem os alunos em suas investigaçóes matemáticas. 
Quadro 2: Atividade para a construção do quadrado

\section{Atividade}

Utilize o comando polígono regular e construa um quadrado. Utilize o comando ângulo e destaque os ângulos internos da figura construída. Utilize o comando distância, comprimento ou perímetro e marque o comprimento dos lados da figura.

Agora clique em um dos vértices e o arraste:

- Em todos os vértices acontece a mesma coisa? Por quê?

- Com a atividade "mover", quais as características que permanecem?

- Nomeie os elementos do quadrado.

Note-se que essa atividade valoriza o arrastar sem um objetivo específico, ou seja, espera-se que os alunos, ao arrastarem os vértices, procurem por regularidades ou por comportamentos que considerarem interessantes. Após algumas tentativas, é possível fazer arrastes para testar as hipóteses levantadas. Também foram acrescentados espaços, na forma de linhas, para que os alunos pudessem escrever suas respostas e suas conclusóes. A escrita, conforme defendem Powell e Bairral (2006), contribui para a reflexão sobre as observações feitas. Não é hábito de professores ou alunos a produção escrita em Matemática, no entanto o grupo Senu + Positivo pensou em incentivar esse processo desde a primeira aula no laboratório. Todos concordaram que, ao escreverem sobre suas experimentaçóes matemáticas, os alunos organizam melhor suas ideias e isso ajuda na justificativa dos resultados encontrados. 
Veja, na Figura 1, como pode ser o desenvolvimento da atividade do Quadro 1.

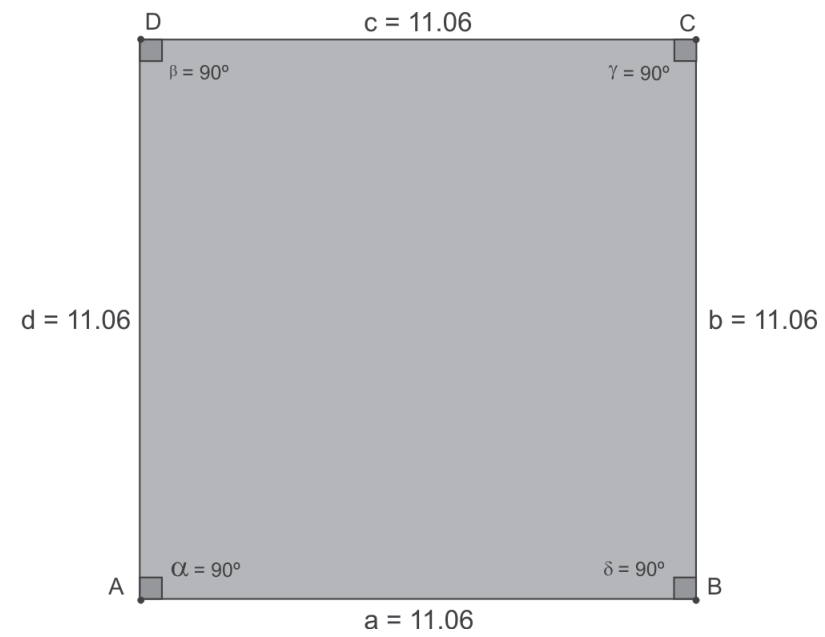

Fig. 1: Construção do quadrado

Depois de construído o quadrado, conforme mostra a Figura 1, os alunos tentam arrastar os vértices e verificam o que acontece. Uma conclusão poderá ser a de que nem todos os vértices podem ser arrastados. Isso acontece porque a construção foi realizada utilizando o comando polígono regular. Com esse recurso, clica-se na janela geométrica do Geogebra, move-se o mouse, com um espaçamento qualquer, e clica-se novamente na janela geométrica. O programa abre uma caixa de comando em que é preciso colocar o número de vértices do polígono regular que se deseja construir. Dessa forma, somente os dois vértices iniciais são considerados pelo software como objetos livres, ou seja, objetos que podem ser arrastados. Os demais vértices são considerados como objetos dependentes e não podem ser movidos. No quadrado da Figura 1, A e B são vértices que podem ser arrastados (objetos livres) e C e $\mathrm{D}$ são vértices que náo podem ser arrastados (objetos dependentes).

$\mathrm{Na}$ Figura 2, o aluno, após arrastar o vértice $\mathrm{A}$, ou o vértice $\mathrm{B}$, ou ambos, poderá perceber que, por mais que se mude a posiçáo do quadrado $\mathrm{ABCD}$, as medidas dos lados e dos ângulos continuam iguais. Depois de concluir isso, ele poderá fazer outros testes, arrastando novamente os vértices para verificar se suas conclusōes estão corretas. 
A partir da conclusão de que os vértices, que são objetos dependentes, não podem ser arrastados, o professor pode pedir aos alunos, em outro momento, a construção de um quadrado em que todos os vértices podem ser arrastados. Vale lembrar que, ao se arrastar qualquer dos vértices, as características de quadrado precisam ser mantidas. Afinal, utilizando o comando polígono, os alunos podem construir um quadrado, mas, ao arrastarem um de seus vértices, perceberão que ele deixa de ser um quadrado e passa a ser um quadrilátero qualquer. Para o grupo, o momento em que os alunos explicam as construções que fizeram é uma ótima oportunidade para se trabalhar a justificação geométrica na construção do quadrado.

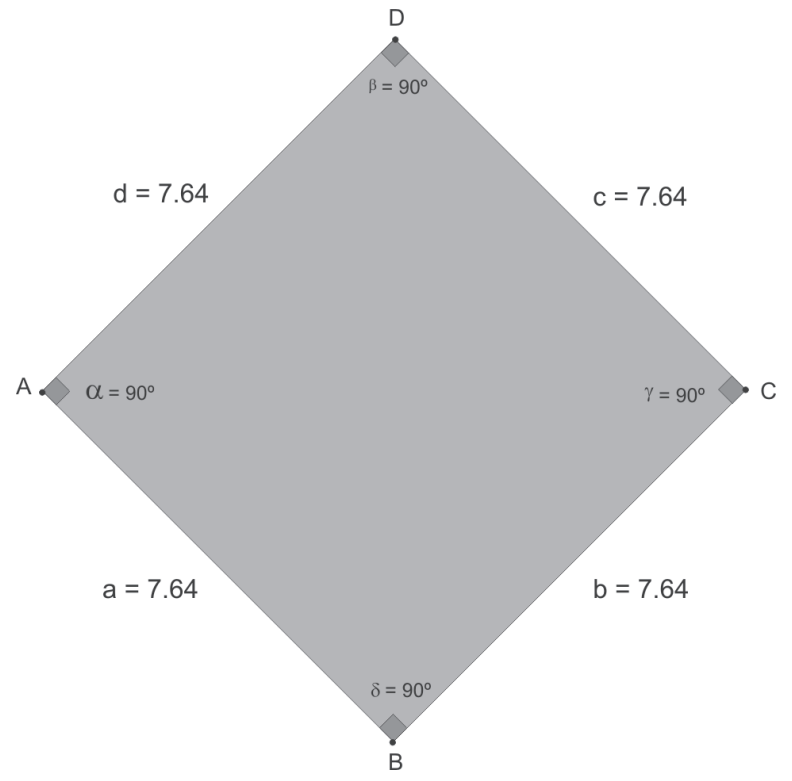

Fig. 2: Construção do quadrado

Noutro exemplo, o Quadro 3 mostra a atividade planejada para ser desenvolvida com o Winplot. Ela foi elaborada para ser aplicada aos alunos do Ensino Médio e seus objetivos compreendem: a) entender como utilizar um parâmetro para animar uma função trigonométrica e b) compreender como se transladam as funçóes trigonométricas seno e cosseno. A atividade descrita no Quadro 3 foi elaborada pelo grupo para alunos que já trabalharam com o software e conhecem seus comandos básicos. 
Quadro 3: Atividade com as funçóes seno e cosseno

Atividade
Utilizando as funçóes seno e cosseno e o comando animaçáo do Winplot, construa
um desenho que represente ondas em movimento. Descreva como você procedeu para
desenvolver essa atividade.

Uma possível construção pode ser vista na Figura 3. As funçôes utilizadas foram $y=a \cdot \operatorname{sen}(x), y=a \cdot \operatorname{sen}(x)+2, y=a \cdot \operatorname{sen}(x)-2, y=a \cdot \cos (x)+1$ e $y=\operatorname{arcos}(x)-1$. A expectativa do grupo é a de que os alunos percebam que existe mais de uma forma de animar a função $y=\operatorname{sen}(x)$. Pode-se multiplicar a funçáo por um parâmetro $a$, obtendo-se $y=a \cdot \operatorname{sen}(x)$. Assim, se $-1 \leq a \leq 1$, tem-se $-1 \leq a \cdot \operatorname{sen}(x) \leq 1$; se $a<-1$ ou $a>1$, tem-se $a \cdot \operatorname{sen}(x)>1$. Pode -se também multiplicar o argumento por um parâmetro $b$, obtendo-se $y=$ $\operatorname{sen}(b . x)$. Essa multiplicação altera o período $p$ da função. Assim, se $-1<b<1$, tem-se um $p>2 \pi$; se $b<-1$ ou $b>1$, tem-se $0<p<2 \pi$.

Ambas as multiplicaçóes daráo a ideia de movimento do gráfico. Se os alunos não perceberem essas conclusóes, o professor pode fazer perguntas como as propostas em Skovsmose (2000): O que acontece se multiplicarmos a função seno por um parâmetro? $\mathrm{O}$ que acontece se multiplicarmos o argumento da função seno por um parâmetro? Pode-se, também, pedir que os alunos façam experimentaçóes e tirem suas conclusóes.

Para transladar a função $y=\operatorname{a.sen}(x)$ duas unidades acima, por exemplo, basta somar 2 à função inicial, obtendo-se $y=a \cdot \operatorname{sen}(x)+2$. Nesse caso, à imagem da função inicial adicionam-se duas unidades. As Figuras 3, 4 E 5 dão a noção das ondas em animação no Winplot, em que os valores de $a$ nas funçôes $y=\operatorname{a\cdot sen}(x), y=a \cdot \operatorname{sen}(x)+2, y=a \cdot \operatorname{sen}(x)-2, y=a \cdot \cos (x)+1$ e $y=$ a.cos(x)- 1 são, respectivamente, $1,0 \mathrm{e}-1$.

Fig. 3

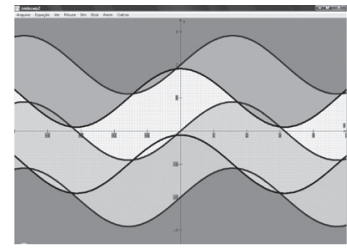

Fig. 4

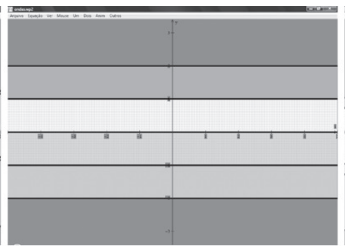

Fig. 5

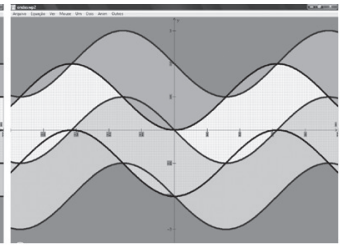

Fig. 3, Fig.4 e Fig.5: Animação de funções seno e cosseno 
Depois de elaborar essas atividades, com seus objetivos e, paralelamente, fazer as construções nos softwares, o grupo concordou com Benedetti (2003, p. 281), na afirmativa de que programas matemáticos possibilitam aos alunos "explorar criticamente certos conceitos e propriedades de funçóes, muitas vezes percorrendo caminhos diversos, caracterizando uma plasticidade que a mídia escrita geralmente não incentiva”.

O grupo, mesmo muito entusiasmado com um possível acréscimo de participação dos alunos na aula, estava consciente de que as potencialidades do computador, associadas a uma abordagem investigativa, implicam em maior atenção do docente, pois os alunos chegam a conclusóes e fazem generalizaçóes que nem sempre valem (Lima, 2009).

\section{Consideraçóes finais}

O trabalho do professor é uma tarefa árdua. Além de lecionar, envolve outras funçôes, como conversar com os pais e/ou responsáveis pelos alunos, elaborar e corrigir as tarefas e provas, participar de reunióes na escola, aconselhar alunos em relação a problemas que enfrentam e que, às vezes, ultrapassam as fronteiras dos conteúdos disciplinares, fazer o planejamento das aulas, dentre outras.

Quanto ao planejamento das aulas, elaborar atividades investigativas para um ambiente informatizado mostrou-se como algo novo para o grupo. Esse exercício gerou certa dificuldade, contudo o trabalho em grupo contribuiu para superar esse desafio. Por exemplo, no primeiro planejamento, nem todos davam opinióes ou faziam observaçóes sobre a tarefa que era formulada. Alguns simplesmente escutavam, outros até bocejavam. Em um momento inicial, essas dificuldades parecem ser comuns. Entretanto, com o decorrer dos encontros, os professores passaram a tomar consciência de que suas consideraçóes contribuem para melhorar a atividade. Observaçóes como "Acho que os alunos ficarão confusos se escrevermos... o melhor seria..." ou "Antes de planejar sobre... é preciso saber o que os alunos sabem sobre..." contribuem para minimizar as falhas que podem ocorrer no processo de ensino. Assim, com o apoio de seus pares, o professor vai se sentindo mais capaz para planejar e experimentar abordagens pedagógicas diferentes daquelas às quais já está habituado. 
Algo que foi consenso para o grupo em todas as reunióes foi o desejo de fazer um planejamento que resultasse em maior participação dos alunos nas aulas. Segundo Imbernón (2006, p. 41), o ato de se preocupar com a participação dos alunos é um fator importante na capacitação profissional do professor. Para ele, essa preocupação envolve um tipo de planejamento que é pensado "não apenas como conteúdo técnico infalível e sim como facilitador de aprendizagem”.

Essa experiência mostra que, mesmo diante de dificuldades enfrentadas pelos professores - como o excesso de trabalho, que engloba desde muitas turmas a muitos alunos por turma, além da falta de tempo, inclusive para o próprio lazer -, o grupo formado se reuniu para refletir sobre possibilidades pedagógicas para a aula de Matemática. Alguns dos participantes tinham de viajar mais de 200 quilômetros para participarem das reunióes presenciais. Mesmo assim, os membros buscaram equilibrar os afazeres de suas vidas para investirem no crescimento profissional.

De acordo com Tardif e Lessard (2007, p. 208), "os professores, queiram ou não, são obrigados a interpretar os programas e adaptá-los continuamente às situaçôes cotidianas". O grupo conseguiu fazer isso ao elaborar fichas de atividades para o ensino de Geometria e de funçóes trigonométricas em um ambiente informatizado. Nesse sentido, esse trabalho mostrou que grupos de estudos podem ser uma ferramenta poderosa para que professores elaborem planejamentos que partam do programa curricular e que é possível adequá-los à realidade de seus alunos.

\section{Referências}

ANDRÉ, M. E. D. A. Texto, contexto e significados: algumas questões na análise de dados qualitativos. Caderno de Pesquisa, São Paulo, n. 45, 1983.

ALVES-MAZZOTTI, A. J.; GEWANDSZNADJDER, F. O Método nas Ciências Naturais e Sociais: pesquisa quantitativa e qualitativa. São Paulo: Pioneira, 1998.

BENEDETTI, F. C. Funçôes, software gráfico e coletivos pensantes. 2003. Dissertação (Mestrado em Educação Matemática) - Universidade Estadual Paulista, Rio Claro, 2003. 
BORBA, M. C. e PENTEADO, M. G. Informática e Educação Matemática. Coleção Tendências em Educação Matemática. Belo Horizonte: Autêntica, 2001.

CHIZZOTTI, A. A Pesquisa Qualitativa em Ciências Humanas e Sociais: Evolução e Desafios. Revista Portuguesa de Educação, Universidade do Minho, Braga, Portugal, v. 16, n. 2, p. 221-236. 2003.

FERREIRA, A. C. Metacognição e desenvolvimento profissional de professores de Matemática: uma experiência de trabalho colaborativo. 2003. Tese (Doutorado em Educação) - Universidade Estadual de Campinas, Campinas, SP, 2003.

FIORENTINI, D. Pesquisar práticas colaborativas ou pesquisar colaborativamente? In: BORBA, M. C.; ARAÚJO, J. L. (Org.). Pesquisa Qualitativa em Educação Matemática. Belo Horizonte: Autêntica, 2004. p. 47-76.

GAMA, R. P. Desenvolvimento profissional com apoio de grupos colaborativos: o caso de professores de Matemática em início de carreira. 2007. Tese (Doutorado em Educação) - Unicamp, Campinas, 2007.

GIMENES, J. Contribuiçôes de um Grupo de Estudos para a Formação Matemática de Professoras que Lecionam nas Séries Iniciais. 2006. Dissertação (Mestrado em Educação Matemática) - Unesp, Rio Claro, 2006.

; PENTEADO, M. G. Aprender Matemática em grupo de estudos: uma experiência com professoras das séries iniciais. Zetetiké, Cempem, Faculdade de Educação, Unicamp, v. 16, n. 29. 2008.

IMBERNÓN, F. Formação Docente e Profissional: formar-se para a mudança e a incerteza, 6. ed. São Paulo: Cortez Editora, 2006.

KENSKI, V. M. Educação e tecnologias: o novo ritmo da informação. Campinas, São Paulo: Papirus, 2007.

LÉVY, Pierre. A Inteligência Coletiva: por uma antropologia do ciberespaço. Tradução de Luiz Paulo Rouanet. São Paulo: Editora Loyola, 1998.

LIMA, L. F. Grupo de estudos de professores e a produção de atividades matemáticas sobre funçóes utilizando computadores. 2009. Dissertação (Mestrado em Educação Matemática) - Unesp, Rio Claro, 2009. 
MURPHY, C. U.; LICK, D. W. Whole faculty study groups: a powerful way to change schools and enhance learning. California: Corwin Press, Inc., 1998.

PONTE, J. P.; BROCADO, J. ; OLIVEIRA, H. Investigaçôes matemáticas na sala de aula. Belo Horizonte: Autêntica, 2003.

; OLIVEIRA, H.; VARANDAS, J. M. O contributo das tecnologias de informação e comunicação para o desenvolvimento do conhecimento e da identidade profissional. In: FIORENTINI, D. (Ed.). Formação de professores de Matemática: Explorando novos caminhos com outros olhares. Campinas: Mercado de Letras, 2003. p. 159-192.

POWELL, A.; BAIRRAL, M. A escrita e o pensamento Matemático: interações e potencialidades. Campinas, SP: Papirus, 2006.

RIBEIRO, M. J. B.; PONTE, J. P. A formação em novas tecnologias e as concepçóes e práticas dos professores. Quadrante, v. 9, n. 2, p. 03-26. 2000.

SKOVSMOSE, O. Cenários para investigação. Boletim de Educação Matemática. São Paulo: Unesp, Rio Claro. 2000.

TARDIF, M.; LESSARD, C. O trabalho docente: elementos para uma teoria da docência como profissão de interaçóes humanas. 3. ed. Petrópolis, RJ: Vozes, 2007.

VALENTE, J. A. (2003).O papel do computador no processo ensino-aprendizagem. Boletim Salto para o Futuro. TV Escola. Brasília: Secretaria de Educação a Distância - SEED. Ministério da Educação. M. Integração das tecnologias na educação. Brasília: MEC/SEED, 2005. Disponível em: www.redebrasil. tv.br/salto/boletins2003/ppm/tetxt3.html. Acesso em: 30 ago. 2008 